\title{
Silício no progresso da mancha marrom na folha bandeira do trigo
}

\author{
Gisele Pereira Domiciano, Fabrício Ávila Rodrigues, Wiler Ribas Moreira, Henrique Vaz de Oliveira, \\ Francisco Xavier Ribeiro do Vale \& Maria Santina Xavier Filha
}

Departamento de Fitopatologia, Universidade Federal de Viçosa, 36570-000, Viçosa, MG, Brasil

Autor para correspondência: Fabrício A. Rodrigues, e-mail: fabricio@ufv.br

\begin{abstract}
RESUMO
Este trabalho teve como objetivo avaliar o efeito do silício ( $\mathrm{Si}$ ) no progresso da mancha marrom, causada por Bipolaris sorokiniana, na folha bandeira de plantas de trigo. Plantas das cultivares de trigo BR-18 e BRS-208 foram crescidas em vasos contendo 0 e $0,30 \mathrm{~g}$ Si $/ \mathrm{kg}$ de solo e inoculadas aos 45 dias após emergência. Avaliou-se a severidade da mancha marrom às 48, 72 e 96 horas após a inoculação das plantas e os dados obtidos foram utilizados para calcular a área abaixo da curva do progresso da mancha marrom (AACPMM). Determinouse também a concentração foliar de Si e cálcio. A concentração de Si na folha bandeira das plantas supridas com Si foi $90,5 \%$ superior do que foi obtido para as plantas não supridas com esse elemento. A severidade da mancha marrom na folha bandeira foi significativamente menor nas plantas supridas com Si em todas as épocas de avaliação. Houve redução de 58,5\% na AACPMM na folha bandeira das plantas supridas com Si. Não houve diferença significativa entre os tratamentos -Si e +Si para a concentração foliar de cálcio. Não houve diferença entre as duas cultivares para a concentração foliar de Si e a AACPMM, mas a concentração foliar de cálcio foi maior para a cultivar BR-18 do que para a cultivar BRS-208. Houve correlação negativa $(r=-0,59)$ entre a concentração foliar de Si e a AACPMM. Com os resultados obtidos nesse estudo, observou-se um efeito positivo do Si em aumentar a resistência da folha bandeira de plantas de trigo à infecção por B. sorokiniana e ao mesmo tempo garantir uma maior produção de grãos dada à importância fisiológica dessa folha, em particular.
\end{abstract}

Palavras-chave: Bipolaris sorokiniana, mancha foliar, nutrição mineral, silicato.

\begin{abstract}
Silicon on the progress of spot blotch on wheat leaf flag

This study aimed to determine the effect of silicon $(\mathrm{Si})$ on the progress of spot blotch, caused by Bipolaris sorokiniana, on wheat leaf flag. Wheat plants of cultivars BR-18 and BRS-208 were grown in pots containing 0 and $0.30 \mathrm{~g} \mathrm{Si} / \mathrm{kg}$ of soil and inoculated at 45 days after emergence. Spot blotch severity was evaluated at 48, 72, and 96 hours after inoculation and data were used to calculate the area under spot blotch progress curve (AUSBPC). The Si and calcium concentrations on leaf tissue were also determined. The Si concentration on leaf flag of plants supplied with Si was $90.5 \%$ higher compared to plants non-supplied with this element. Spot blotch severity was significantly lower on leaf flags of plants supplied with $\mathrm{Si}$ at all evaluation times. There was a reduction of 58.5\% in AUSBPC on leaf flag of plants supplied with Si. There was no significant difference between -Si and +Si treatments for calcium concentration on leaf tissue. There was no significant difference between the two cultivars for Si concentration on leaf tissue and AUSBPC, but calcium concentration on leaf tissue was higher for cultivar BR-18 than for cultivar BRS-208. The correlation between Si concentration on leaf tissue and AUSBPC was negative $(\mathrm{r}=-0.59)$. The results of this study showed a positive effect of $\mathrm{Si}$ on increasing wheat leaf flag resistance against infection by $B$. sorokiniana, considering the importance of this leaf in particular for a gain in yield.
\end{abstract}

Keywords: Bipolaris sorokiniana, foliar disease, mineral nutrition, silicate.

A mancha marrom, causada pelo fungo Bipolaris sorokiniana (Sacc.) Shoemaker, é uma das principais doenças foliares da cultura do trigo com ocorrência predominante em regiões quentes e úmidas (Wiese, 1987; Kumar et al., 2002). Os sintomas dessa doença iniciam-se com pequenas manchas ovais de 3 a $4 \mathrm{~mm}$ e de coloração marrom-escuro a negra tanto nas folhas quanto nas bainhas

Parte da Dissertação de Mestrado do primeiro autor. Universidade Federal de Viçosa. Viçosa MG. 2008. e no colmo das plantas de trigo. Essas manchas expandem, tornando-se elípticas e com abundante esporulação do fungo. Quando ocorre a coalescência das lesões, a folha torna-se seca (Bockus et al., 2010). Além dos sintomas foliares, ocorre também a podridão radicular causando a morte prematura das plantas. $\mathrm{Na}$ presença de condições favoráveis, as espiguetas também podem ser infectadas, o que leva o abortamento dos grãos (Kumar et al., 2002). O uso de fungicidas, sementes sadias, rotação de culturas e cultivares com resistência parcial são as principais medidas empregadas para o manejo da doença visando minimizar as perdas na produção (Bockus et al., 2010). 
De acordo com Bancal et al. (2007), os carboidratos formados no período da pré-antese são realocados para os grãos de trigo independente da ocorrência ou não da epidemia de doenças foliares. Assim, fica demonstrada a importância das folhas dos diferentes dosseis da planta de trigo para o eficiente acúmulo de reservas na pré-antese que mais tarde serão remobilizadas para o completo enchimento dos grãos. Os autores ainda propuseram um modelo simples baseado na área foliar verde por camada do dossel e nas reservas pré-antese para predizer tanto o crescimento quanto a produtividade de plantas de trigo afetada pelas doenças foliares tardias.

A duração e a largura da folha bandeira são duas variáveis utilizadas para estimar a produção e a qualidade dos grãos de trigo devido à alta correlação entre essas variáveis com o acúmulo de proteínas nos grãos (Blake et al., 2007; Zencirci, 2008). A duração da área foliar é de grande importância, pois a folha bandeira é a última folha a entrar em senescência e é capaz de intercepta mais luz do que as folhas baixeiras (Blandino \& Reyneri, 2009). Devido a sua proximidade a espiga, a translocação de nutrientes contribui com cerca de 30 a $50 \%$ dos fotoassimilados para o enchimento dos grãos. Manter a sanidade da parte aérea do trigo, incluindo a folha bandeira, é importante para aumentar a produção e a qualidade dos grãos considerando que a severidade de doenças tem grande impacto na fotossíntese bem como em outros importantes processos metabólicos que ocorrem nas plantas (Domiciano et al., 2009).

Considerando que as doenças economicamente importantes como a brusone, a queima das bainhas e a mancha parda no arroz, além da antracnose do sorgo têm sido eficientemente controladas pelo fornecimento de silício (Si) às plantas (Datnoff et al., 2007; Resende et al., 2009), este elemento passa a ter papel relevante também na potencialização de respostas de defesa à diversos patógenos (Datnoff et al., 2007). O suprimento de Si às plantas de trigo também foi eficiente em reduzir a severidade da mancha marrom (Domiciano et al., 2010). Este trabalho teve como objetivo avaliar o efeito do $\mathrm{Si}$ em reduzir a severidade da mancha marrom nas folhas bandeira de plantas de trigo, considerando a falta de informação dessa natureza na literatura.

Plantas de trigo das cultivares BR-18 e BRS-208, suscetíveis a mancha marrom, foram crescidas em vasos plásticos contendo solo deficiente em Si pertencente à classe Latossolo Amarelo ácrico típico coletado no município de Uberlândia, Minas Gerais. As características químicas desse solo são: $\mathrm{pH}$ em $\mathrm{KCl}=4,8 ; \mathrm{P}$ (Mehlich-1) $=0,5 \mathrm{mg} / \mathrm{dm}^{3}$; $\mathrm{K}\left(\right.$ Mehlich-1) $=13 \mathrm{mg} / \mathrm{dm}^{3} ; \mathrm{Al}^{3+}, \mathrm{Ca}^{2+}, \mathrm{Mg}^{2+}, \mathrm{H}+\mathrm{Al}^{3+}=$ 0,$1 ; 0,0 ; 0,0$ e $3,8 \mathrm{cmol} / \mathrm{dm}^{3}$, respectivamente; saturação de bases $=2 \%$ e matéria orgânica $=2.3 \mathrm{dag} / \mathrm{kg}$. A concentração de $\mathrm{Si}$, extraído em $\mathrm{CaCl}_{2}$, foi de $11,8 \mathrm{mg} / \mathrm{dm}^{3}$. A fonte de $\mathrm{Si}$ usada foi a volastonita (silicato de cálcio; Vansil, EW-20, Ipiranga São Paulo, Brasil) cuja composição química é de $24,2 \%$ de $\mathrm{Si}$ e $31 \%$ de $\mathrm{Ca}$. A volastonita foi incorporada ao solo na dose de $1,25 \mathrm{~g} / \mathrm{kg}$ de solo, o que correspondeu à dose de $0,30 \mathrm{~g} \mathrm{Si} / \mathrm{kg}$ de solo por vaso. Ao solo que não recebeu volastonita, foi incorporado carbonato de cálcio $(40 \% \mathrm{Ca}$, Sigma-Aldrich, St. Louis, MO) na dose de $0,97 \mathrm{~g} / \mathrm{kg}$ de solo para equilibrar a concentração de Ca presente no tratamento que recebeu 1,25 g de volastonita. Assim, a concentração deste elemento entre os tratamentos ficou padronizada em $0,39 \mathrm{~g}$ de $\mathrm{Ca} / \mathrm{kg}$ de solo. O solo de cada vaso foi incubado por 60 dias em $60 \%$ da capacidade de campo.

Após este período, foram semeadas quatro sementes de trigo de cada cultivar previamente desinfestadas em hipoclorito de sódio 4\% (v/v) em cada vaso. Cinco dias após a emergência, efetuou-se o desbaste, deixando-se apenas duas plantas por vaso. O solo foi fertilizado com 1,63 g de fosfato de cálcio por vaso e $30 \mathrm{~mL}$ de solução nutritiva contendo, em g/L, $6,4 \mathrm{KCl} ; 3,8 \mathrm{~K}_{2} \mathrm{SO}_{4} ; 5,01 \mathrm{MgSO}_{4} \cdot 7 \mathrm{H}_{2} \mathrm{O}$; $2,03\left(\mathrm{NH}_{2}\right)_{2} \mathrm{CO} ; 0,009 \mathrm{NH}_{4} \mathrm{MO}_{7} \mathrm{O}_{24} \cdot 4 \mathrm{H}_{2} \mathrm{O} ; 0,054 \mathrm{H}_{3} \mathrm{BO}_{3}$; $0,222 \mathrm{ZnSO}_{4} \cdot 7 \mathrm{H}_{2} \mathrm{O} ; 0,058 \mathrm{CuSO}_{4} \cdot 5 \mathrm{H}_{2} \mathrm{O}$ e $0,137 \mathrm{MgCl}_{2}$ $4 \mathrm{H}_{2} \mathrm{O}$. Um volume de $15 \mathrm{~mL}$ de solução contendo $0,27 \mathrm{~g}$ de $\mathrm{FeSO}_{4} \cdot 7 \mathrm{H}_{2} \mathrm{O}$ e $0,37 \mathrm{~g}$ de EDTA bisódico $\mathrm{L}^{-1}$ também foi adicionado à cada vaso após a emergência das plantas e também aos 35 dias quando as plantas encontravam-se no estádio de crescimento 35 (Zadoks, 1974).

$O$ inóculo de $B$. sorokiniana foi preparado adicionando-se $20 \mathrm{~mL}$ de água destilada esterilizada em cada placa de Petri contendo o fungo em crescimento com posterior fricção com pincel de cerdas grossas para liberação dos conídios. À suspensão foi acrescida gelatina (1\% p/v) para aumentar a aderência dos conídios na superfície foliar. Em seguida, a concentração foi ajustada para 2,5 $\times 10^{4}$ conídios $/ \mathrm{mL}$ com auxílio de hemacitômetro. Plantas com 45 dias de idade (estádio de crescimento 41) (Zadoks, 1974) foram inoculadas com o patógeno utilizando-se um atomizador VL Airbrush (Paasche Airbrush Co, Chicago, IL, USA). Após a inoculação, as plantas foram cobertas com sacos plásticos borrifados com água e, em seguida, transferidas para câmara de crescimento (temperatura de $25 \pm 2^{\circ} \mathrm{C}$, umidade relativa de $70 \%$ e fotoperíodo de $12 \mathrm{~h}$ luz/12 h escuro com lâmpadas fluorescentes de 40 watts) onde permaneceram por $48 \mathrm{~h}$. Após esse período, os sacos plásticos foram removidos e as plantas permaneceram nessa mesma câmara de crescimento até o final das avaliações.

Avaliou-se a severidade da mancha marrom às 48, 72 e 96 horas após a inoculação (h.a.i.) das folhas bandeira dos dois perfilhos principais de cada planta utilizandose uma escala de severidade (IRRI, 1996). No final das avaliações, as folhas das plantas de trigo das repetições de todos os tratamentos foram coletadas para determinação da concentração foliar de $\mathrm{Si}$ e de $\mathrm{Ca}$. O material vegetal foi seco em estufa a $70^{\circ} \mathrm{C}$ até atingir peso constante e, posteriormente, triturado em moinho tipo Wiley. A concentração foliar de Si foi determinada pela metodologia proposta por Korndörfer et al. (2004) e a de $\mathrm{Ca}$ foi determinada por espectrometria de absorção atômica.

Os dados de severidade foram utilizados para calcular a área abaixo da curva do progresso da mancha marrom (AACPMM). Os dados obtidos foram submetidos à análise 
de variância (ANOVA) e as médias comparadas pelo testet ao nível de 5\% de probabilidade. A concentração foliar de Si foi correlacionada com a AACPMM. O experimento foi instalado em delineamento inteiramente casualizado num esquema fatorial $2 \times 2$ com três repetições. Os fatores estudados foram: duas cultivares de trigo e plantas supridas (+Si) ou não (-Si) com Si. Cada repetição foi constituída por um vaso plástico contendo duas plantas de trigo. $\mathrm{O}$ experimento foi repetido e os dados da concentração de Si e $\mathrm{Ca}$ e da AACPMM foram combinados após ser confirmada a homogeneidade de variância pelo teste de Bartlett (Gomez \& Gomez, 1994).

Não houve interação significativa $(P \geq 0,05)$ entre os fatores cultivares de trigo e suprimento ou não de $\mathrm{Si}$ às plantas para as variáveis concentração foliar de $\mathrm{Si}$ e de $\mathrm{Ca}$ e AACPMM. A concentração de Si nas folhas bandeira das plantas supridas com Si foi 90,5\% superior do que foi obtido para as plantas não supridas com esse elemento (Tabela 1). Rodrigues et al. (2001) encontraram valores variando de 1 a $1,5 \%$ de $\mathrm{Si}$ em folhas de trigo de plantas crescidas na presença de Si. Concentração foliar de Si em até $2 \%$ está associada com a capacidade fisiológica inata das plantas de trigo em absorver o Si da solução nutritiva (Rafi \& Epstein, 1999) ao contrário das plantas de arroz que chegam apresentar até $10 \%$ de Si nas folhas (Dallagnol et al., 2009). A severidade da mancha marrom na folha bandeira foi significativamente reduzida nas plantas das duas cultivares supridas com $\mathrm{Si}$ em todas as épocas de avaliação (Figura 1). Na concentração de até $1,2 \%$ de $\mathrm{Si}$, verificou-se uma redução de 58,5\% na AACPMM nas folhas bandeira. Não houve diferença significativa $(P \geq 0,05)$ entre os tratamentos -Si e +Si para a concentração foliar de Ca (Tabela 1), assim a redução na severidade da mancha marrom e da AACPMM deve ser atribuída exclusivamente ao Si.

Sabe-se que o ácido monosilícico compete com o Ca pelos sítios de ligações na parede celular devido a

TABELA 1 - Concentração foliar de silício $(\mathrm{Si})$ e de cálcio $(\mathrm{Ca})$ e área abaixo da curva do progresso da mancha marrom (AACPMM) em folhas bandeira de plantas de trigo das cultivares BR-18 e BRS-208 supridas (+Si) ou não (-Si) com silício

\begin{tabular}{|c|c|c|c|}
\hline \multirow{2}{*}{$\begin{array}{l}\text { Fatores } \\
\text { Silício }\end{array}$} & \multicolumn{2}{|c|}{ Concentração (\%) } & \multirow[t]{2}{*}{ ААСРММ } \\
\hline & $\mathrm{Ca}$ & $\mathbf{S i}$ & \\
\hline$-\mathrm{Si}$ & 0,76 & 0,63 & 59,14 \\
\hline$+\mathrm{Si}$ & 0,77 & 1,20 & 24,6 \\
\hline$t$-test & $0,25^{\mathrm{ns}}$ & $18,73^{*}$ & $3,83^{*}$ \\
\hline \multicolumn{4}{|l|}{ Cultivares } \\
\hline BR-18 & 0,89 & 0,92 & 48,52 \\
\hline BRS-208 & 0,64 & 0,90 & 36,10 \\
\hline$t$-test & $7,88^{*}$ & $0,20^{\mathrm{ns}}$ & $1,82^{\mathrm{ns}}$ \\
\hline $\mathrm{CV}(\%)$ & 16,51 & 13,43 & 47,27 \\
\hline
\end{tabular}

$\mathrm{CV}=$ coeficiente de variação.

ns $=$ não significativo, ${ }^{*}=$ significativo a $P \leq 0.05$.
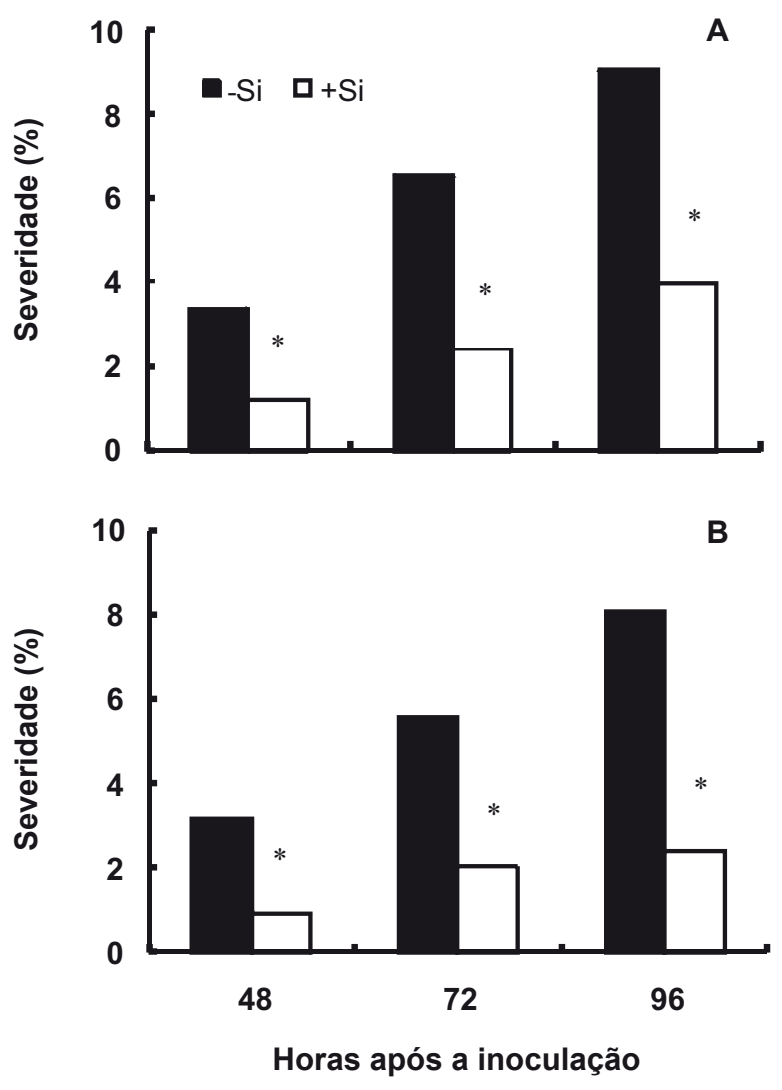

FIGURA 1 - Severidade da mancha marrom nas folhas bandeira de plantas de trigo das cultivares BR-18 (A) e BRS-208 (B) supridas $(+\mathrm{Si})$ ou não $(-\mathrm{Si})$ com silício. A diferença estatística, pelo teste $t(P>0,05)$, entre os tratamentos $-\mathrm{Si}$ e $+\mathrm{Si}$ para cada cultivar e época de avaliação está representada por um asterisco.

sua facilidade em complexar-se com alcoóis polihídricos, ácidos orgânicos, lignina, carboidratos e até mesmo certos compostos fenólicos (Inanaga \& Okasaka, 1995). Não houve diferença significativa $(P \geq 0,05)$ entre as duas cultivares para a concentração foliar de Si e a AACPMM; entretanto a concentração foliar de $\mathrm{Ca}$ foi significativamente superior para a cultivar BR-18 do que para a cultivar BRS208. A correlação entre a concentração foliar de $\mathrm{Si}$ com a AACPMM foi negativa $(\mathrm{r}=-0,59 ; P=0,03)$. Relatos na literatura corroboram os resultados do presente trabalho indicando o potencial do $\mathrm{Si}$ em reduzir a severidade de algumas doenças economicamente importantes em culturas como o arroz, a cevada, o milho, o sorgo e o trigo (Datnoff et al., 2007; Resende et al., 2009; Domiciano et al., 2010).

Wegulo et al. (2009), estudando perdas na produção de grãos em plantas de trigo em diferentes estágios de crescimento e infectadas por $B$. sorokiniana, observaram que do estádio de crescimento 31 ao estádio 39 de acordo com Zadoks (1974), as perdas na produção foram maiores do que em outros estágios de crescimento. A aplicação de fungicidas nesta fase da cultura foi importante para incrementar a produção de grãos. Como ocorre a emissão 
da folha bandeira nessa fase da cultura, essa pode ter contribuído para um incremento na produção uma vez que ela é responsável por até $50 \%$ do carbono utilizado no enchimento dos grãos (Zencirci, 2008). Os resultados obtidos nesse estudo abrem perspectivas para o uso do $\mathrm{Si}$ em um sistema de manejo integrado da mancha marrom, principalmente considerando a folha bandeira como órgão de grande importância para a planta de trigo garantir um aumento na produção de grãos. Considerando o potencial do Si como uma medida de controle a ser utilizada no manejo integrado da mancha marrom, experimentos em campo são necessários para complementar os resultados obtidos em condições controladas. Aliado a outras estratégias de controle, a aplicação de Si dentro da filosofia de uma Agricultura sustentável poderá contribuir para reduzir o número de pulverizações com fungicidas e o custo de produção.

\section{AGRADECIMENTOS}

Os autores F.A.R. e F.X.R.V. agradecem ao Conselho Nacional de Desenvolvimento Científico e Tecnológico - CNPq pela bolsa de produtividade em pesquisa. G.P.D. e M.X.X.F. agradecem ao CNPq pela bolsa de Mestrado. Os autores agradecem ao $\mathrm{CNPq}$, a Coordenação de Aperfeiçoamento de Pessoal de Nível Superior - CAPES e a Fundação de Amparo à Pesquisa do Estado de Minas Gerais - FAPEMIG pelo recurso financeiro.

\section{REFERÊNCIAS BIBLIOGRÁFICAS}

Bancal MO, Robert C, Ney B (2007) Modelling wheat growth and yield from late epidemics of foliar diseases using loss of green leaf area per layer and pre-anthesis reserves. Annals of Botany 100:777-789.

Blake NK, Lanning SP, Martin JM, Sherman JD, Talbert LE (2007) Relationship of flag leaf characteristics to economically important traits in two spring wheat crosses. Crop Science 47:491-496.

Blandino M, Reyneri A (2009) Effect of fungicide and foliar fertilizer application to winter wheat at anthesis on flag leaf senescence, grain yield, flour bread-making quality and DON contamination. European Journal of Agronomy 30:275-282.

Dallagnol LJ, Rodrigues FA, Mielli MVB, Ma JF, Datnoff LE (2009) Defective active silicon uptake affects some components of rice resistance to brown spot. Phytopathology 99:116-121.

Datnoff LE, Rodrigues FA, Seebold KW (2007) Silicon and Plant Disease In: Datnoff LE, Elmer WH, Huber DM (Eds.) Mineral Nutrition and Plant Disease. Saint Paul MN. APS Press. pp. 233246.
Domiciano GP, Resende RS, Rodrigues FA, DaMatta FM (2009) Alterações na fotossíntese de plantas infectadas por fitopatógenos. Revisão Anual de Patologia de Plantas 17:305-339.

Domiciano GP, Rodrigues FA, Vale FXR, Xavier Filha MS, Moreira WR, Andrade CCL, Pereira SC (2010). Wheat resistance to spot blotch potentiated by silicon. Journal of Phythopathology 158:334-343.

Gomez KA, Gomez AA (1994) Statistical Procedures for Agricultural Research, $2^{\text {nd }}$ Ed. New York NY. Wiley.

Inanaga S, Okasaka A (1995) Calcium and silicon binding compounds in cell walls of rice shoots. Japanese Journal of Soil Science and Plant Nutrition 41:103-110.

International Rice Research Institute - IRRI (1996) Standard Evaluation System for Rice. International Rice Research Institute.

Korndörfer GH, Pereira HS, Nola A (2004) Análise de silício: solo, planta e fertilizante. Uberlândia MG. Universidade Federal de Uberlândia. Boletim Técnico.

Kumar J, Schafer P, Huckelhoven R, Langen G, Baltruschat H, Stein E, Nagarajan S, Kogel KH (2002) Bipolaris sorokiniana, a cereal pathogen of global concern: cytological and molecular approaches towards better control. Molecular Plant Pathology $3: 185-195$

Macgrath MT, Pannypacker SP (1991) Reduction in the rate and duration of grain growth in wheat due to stem rust and leaf rust. Phytopathology 81:778-787.

Rafi MM, Epstein E (1999) Silicon absorption by wheat (Triticum aestivum L). Plant and Soil 211:223-230.

Resende RR, Rodrigues FA, Soares JM, Casela CR (2009) Influence of silicon on some components of resistance to anthracnose in susceptible and resistant sorghum lines. European Journal of Plant Pathology 124:533-541.

Rodrigues FA, Korndörfer GH, Corrêa GF, Buki GB, Silva OA, Datnoff LE (2001) Response of six gramineae species to application of calcium metasilicate In: Datnoff LE, Snyder GH, Korndörfer GH (Eds.) Silicon in Agriculture. Amsterdam. Elsevier Science BV Studies in Plant Science.

Bockus WW, Bowden RL, Hunger RM, Morril WL, Murray TD, Smiley RW (2010) Compendium of wheat diseases and Pests. $3^{\text {rd }}$ Ed. Saint Paul MN. APS Press.

Zadoks JC, Chang TT, Konzac CF (1974) A decimal code for the growth stages of cereals. Weed Research 14:415-421.

Zencirci N (2008) Effect of upper plant parts on yield and quality in Turkish durum wheat landraces from different regions, altitudes, and Provinces. Turkish Journal of Agriculture and Forestry 32:2939.

Wegulo SN, Breathnach JL, Baenziger PS (2009) Effect of growth stage on the relationship between tan spot and spot blotch severity and yield in winter wheat. Crop Protection 28:696-702.

TPP 9124 - Recebido 22 Setembro 2009 - Aceito 13 Maio 2010 Editor de Seção: José Maurício Fernandes 